\title{
Promoting Instrument Development for New Research Avenues in Ocean Science: Opening the Black Box of Grazing
}

\author{
Susanne Menden-Deuer ${ }^{1 *}$, Wayne Homer Slade ${ }^{2}$ and Heidi Dierssen ${ }^{3}$ \\ ' Graduate School of Oceanography, University of Rhode Island, Narragansett, RI, United States, ${ }^{2}$ Sequoia Scientific, Inc., \\ Bellevue, WA, United States, ${ }^{3}$ Department of Marine Sciences, University of Connecticut, Groton, CT, United States
}

OPEN ACCESS

Edited by:

Oscar Schofield,

Rutgers, The State University

of New Jersey, United States

Reviewed by:

Christoph Waldmann,

University of Bremen, Germany

John Conroy,

Virginia Institute of Marine Science,

William \& Mary, United States

${ }^{*}$ Correspondence:

Susanne Menden-Deuer

smenden@uri.edu

Specialty section

This article was submitted to

Ocean Observation

a section of the journal

Frontiers in Marine Science

Received: 15 April 2021

Accepted: 20 July 2021

Published: 26 August 2021

Citation:

Menden-Deuer S, Slade WH and

Dierssen H (2021) Promoting

Instrument Development for New

Research Avenues in Ocean Science:

Opening the Black Box of Grazing.

Front. Mar. Sci. 8:695938.

doi: 10.3389/fmars.2021.695938
While recent research has provided increasing insight into ocean ecosystem functions and rapidly improving predictive ability, it has become clear that for some key processes, including grazing by zooplankton, there simply is no currently available instrumentation to quantify relevant stocks and rates, remotely or in situ. When measurement capacity is lacking, collaborative research between instrument manufacturers and researchers can bring us closer to addressing key knowledge gaps. By necessity, this high risk, high rewards research will require iterative steps from best case scenarios under highly controlled and often artificial laboratory conditions to empirical verification in complex in situ conditions with diverse biota. To illustrate our point, we highlight the example of zooplankton grazing in marine planktonic food webs. Grazing by singlecelled zooplankton accounts for the majority of organic carbon loss from marine primary production but is still measured with logistically demanding, point-sample incubation methods that result in reproducible results but at insufficient resolution to adequately describe temporal and spatial dynamics of grazer induced impacts on primary production, export production and the annual cycle of marine plankton. We advance a collaborative research and development agenda to eliminate this knowledge gap. Resolving primary production losses through grazing is fundamental to a predictive understanding of the transfer of matter and energy through marine ecosystems, major reservoirs of the global carbon cycle.

Keywords: grazing, ocean optics, remote sensing, phytoplankton, zooplankton, inherent optical properties, primary production

\section{INTRODUCTION}

Grazing remains one of the key unknowns in global predictive models of carbon flux, food web structure and ecosystem characteristics, because empirical grazing measurements are sparse, resulting in poor parameterization of grazing functions (e.g., Stock and Dunne, 2010; Bisson et al., 2020). To overcome this critical knowledge gap, we suggest focused effort be placed on the development of instrumentation that can link changes in phytoplankton biomass or optical properties with grazing. We contend that to gain a mechanistic understanding of ocean production and carbon fluxes, targeted, empirically validated instrument design, and model development is needed on how grazing influences the optical properties of the water column directly. The ultimate goal is to leverage linkages between grazing and optical properties to predict grazing using remote and autonomous sensors on a global scale. 
Grazing is a central, rate-setting process in ocean ecosystems and a driver of marine biogeochemical cycling (Worden et al., 2015). In all ocean ecosystems, grazing by heterotrophic protists constitutes the single largest loss factor of marine primary production and alters particle size distributions (PSD; Steinberg and Landry, 2017). Grazing affects all pathways of export production, rendering grazing important both for surface and deep carbon processes (Mariani et al., 2013). Predicting central paradigms of ocean ecosystem function, including responses to environmental change requires accurate representation of grazing in global biogeochemical, ecosystem and cross-biomecomparison models (e.g., Stock and Dunne, 2010). Several largescale analyses have concluded that phytoplankton losses, which are dominated by grazing are the putative explanation for annual cycles in phytoplankton biomass, accumulation rates and export production (Behrenfeld, 2010; Mignot et al., 2018; Bisson et al., 2020). While these analyses were based on in situ or remote observations, none quantified grazing empirically.

We hypothesize that grazing influences the absorption coefficients and scattering functions of seawater due to changes in the relative amounts and spectral slopes of detrital, colored dissolved and particulate materials through grazer release of dissolved matter, size-selective removal of phytoplankton, fractionation of cells and breakdown of cellular constituents during grazing (Figure 1). Hence, different amounts of cellular materials will be released into the water, changing the PSD and vertical structure of phytoplankton, as well as detrital and dissolved materials. Developing proxies of grazing from changes in optical properties can enable approximating grazing over large spatial and temporal scales using in situ or remote observational technology. To date, there are no approaches that support direct retrieval of grazing related signals from space or autonomous in situ instrumentation (Brewin et al., 2021). To alleviate this important limitation, we outline a suggested empirical approach that demonstrates how iterative laboratory experiments, field testing and modeling can provide grazing proxies for existing in situ and remote sensing applications. A case for collaboration between the research community and industrial partners is interwoven within this approach, wherein the industrial partners are closely involved with the basic research and experimental design to better inform instrument development to expand observational capabilities to achieve the research goals. Such industry-research partnerships are essential for research where the applicability of currently available instrumentation is unknown. We conclude by highlighting some of the benefits and challenges of these collaborative relationships.

\section{GRAZING}

\section{Background}

Grazing is the term used to describe the consumption of phytoplankton by zooplankton, although a broader application of the term is common. This removal of phytoplankton can be measured in terms of abundance (i.e., cells), biomass [e.g., Carbon (C)] or biomass proxies (e.g., Chl a). Zooplankton are diverse including single celled protozoans such as flagellates and ciliates, as well as multi-cellular crustaceans such as copepods and krill and gelatinous forms, including salps and ctenophores. While single celled protozoans typically number in the 100 to 1,000 per $\mathrm{mL}$, abundance of multi-cellular types is typically orders of magnitude lower, although aggregations can result in high density patches and swarms. Each zooplankton group differs in fundamental aspects, such as sexual or asexual reproduction, which can yield exponential population increases for single-celled types. The single-celled zooplankton, protists, have garnered particular attention because through exponential growth they can rapidly match increases in phytoplankton abundance, such as during the development of a bloom. We will refer to these here as "herbivorous protists" and identify them as particularly important in understanding particle concentrations in the ocean. Not only do these single celled organisms reproduce asexually and exponentially, they also modify the abundance, size and species composition of their phytoplankton prey (Menden-Deuer and Kiørboe, 2016). Grazing involves a great deal of selectivity and feeding strategies differ broadly, including filter feeding of large volumes of water or uptake of individual particles in a raptorial fashion. While most zooplankton eat prey that is 10 -fold smaller in body size, some dinoflagellates can eat phytoplankton, especially large diatoms that are 10-fold larger than their body size (Menden-Deuer et al., 2005), which means that the largest phytoplankton particles can still be grazed by herbivorous protists. Thus, grazing alters PSD (Morison et al., 2020), which is of key importance to optical backscattering properties and remote sensing (Dall'Olmo et al., 2009; Buonassissi and Dierssen, 2010; Slade et al., 2015).

Our focus on herbivorous protist grazing is motivated by their vastly greater impact on primary production. Grazing by herbivorous protists is known to be the largest loss factor of primary production, removing on average $\sim 66 \%$ of global primary production (Calbet and Landry, 2004) compared to $<10 \%$ removal of primary production contributed by multicellular zooplankton (Calbet, 2001). Of course these estimates have high variance and exceptions occurr in time and space. Model analyses suggest that the majority of $\mathrm{C}$ export due to grazing may be due to microzooplankton (Bisson et al., 2020). This may be rooted in the fact that over $25 \%$ of the biomass ingested by microzooplankton can be re-excreted (Strom et al., 1997). Protists are important conduits in transferring organic matter across trophic levels (Steinberg and Landry, 2017) and grazing persists in removing organic matter in the ocean's twilight zone (McNair and Menden-Deuer, 2020). Predation by herbivorous protists has a significant impact on both dissolved and particulate phases of seawater constituents (Verity, 1986; Strom, 2007; Mariani et al., 2013). Effects on PSD and the nature of protistan fecal material are poorly constrained, but is likely to have substantive effects on the optical properties of the dissolved and particulate phase of seawater (Figure 2).

Herbivorous protists have become a prime target for grazing studies, based on their high abundance, capacity for exponential growth and ability to feed on the full spectrum of planktonic particles. These features have implications for grazing effects on the abundance and composition of phytoplankton communities 


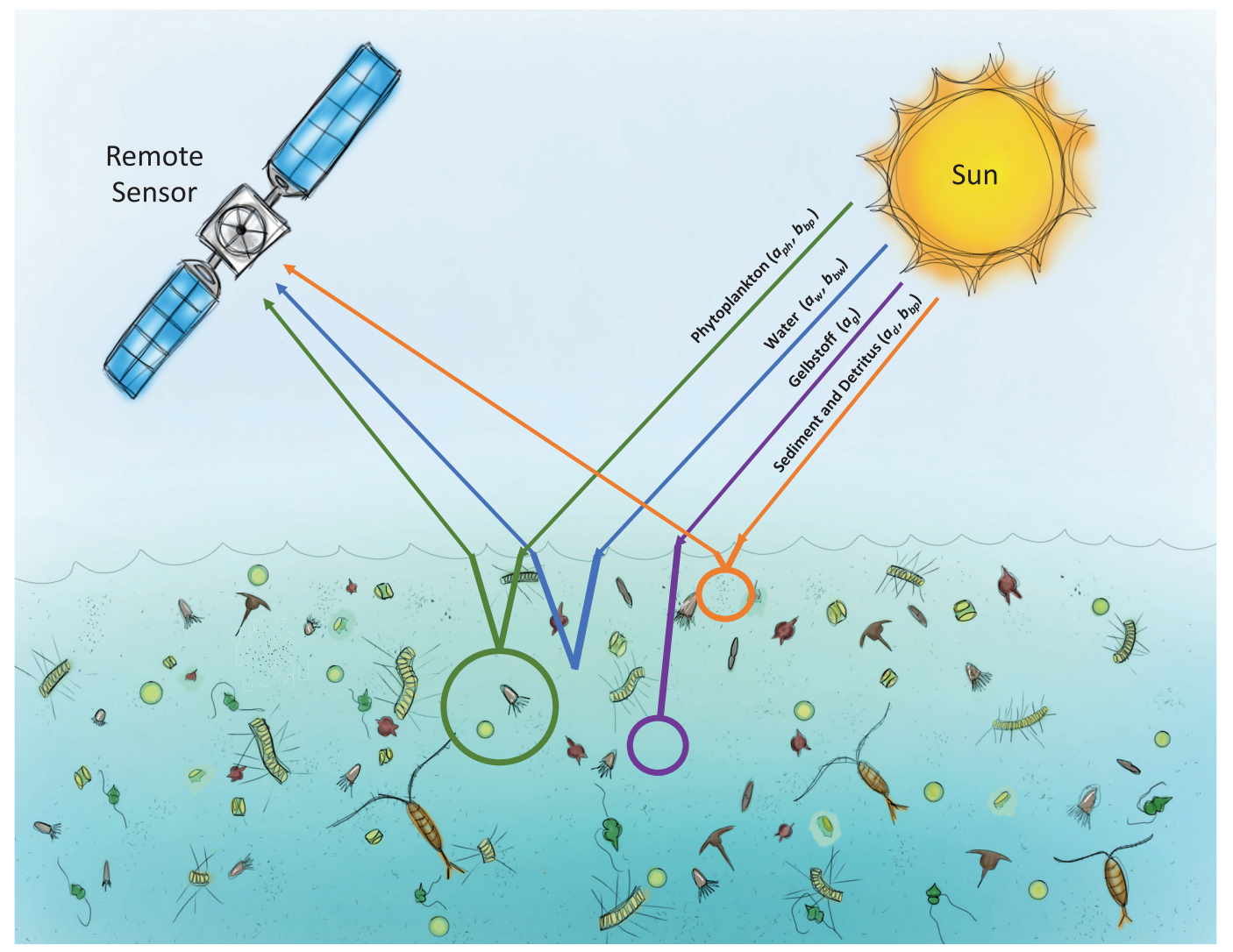

FIGURE 1 | Schematic of how common seawater constituents, including particulate and dissolved components, could both be generated and altered through the process of herbivorous grazing.

and the PSD, as well as effects on the optical properties of the dissolved phase.

\section{Grazing Rate Measurement}

Despite ample evidence of the importance of herbivorous predation on phytoplankton, we lack a mechanistic understanding and predictive ability of the quantitative effects of predation on primary production, due to the lack of adequate measurement technology. Although grazing in diverse zooplankton has been studied for decades, measurements rely on incubation based methods that have been refined but fundamentally did not change over time (Frost, 1972; Landry and Hassett, 1982). The currently most widely used method to study grazing in herbivorous protists is the dilution method, which involves contrasting phytoplankton growth and mortality in bottle incubations at manipulated grazer concentrations (Landry and Hassett, 1982; Morison and Menden-Deuer, 2017). Although the dilution method has yielded remarkable insights into the environmental drivers and quantitative importance of grazing in ocean ecosystems (e.g., Landry et al., 2009; Morison et al., 2019) and generated intriguing hypotheses (e.g., Behrenfeld, 2010), incubation based methods pose logistical challenges that result in limited sampling on a global scale (Schmoker et al., 2013). These methods all rely on capturing and handling organisms and incubating them under controlled and defined conditions. These characteristics imply that grazing estimates could well be affected by experimentally induced biases, although Lagrangian grazing studies, comparing in situ and incubation based plankton population dynamics typically show good agreement and reliability of the bottle incubation approach (Landry et al., 2009; Morison et al., 2019; McNair et al., 2021). Although reliable, due to logistical constraints and the need for incubation, grazing measurements are limited in their spatial and temporal resolution. Clearly, measuring grazing one bottle at a time is no means to understanding fundamental ecosystem process in a global context across seasons and habitats. Autonomous in situ and remote sensing capabilities provide a unique opportunity to increase the quantity and resolution of grazing rate measurements. To do so, there is an urgent need to examine the effects of grazing on optical properties of seawater and to leverage optical and ultimately remote sensing approaches to quantify grazing on the global scale.

\section{OPTICAL PROPERTIES}

Although planktonic grazers affect both the dissolved and particulate constituents of seawater, little is known about grazing influences on seawater optical properties. Although sequential 

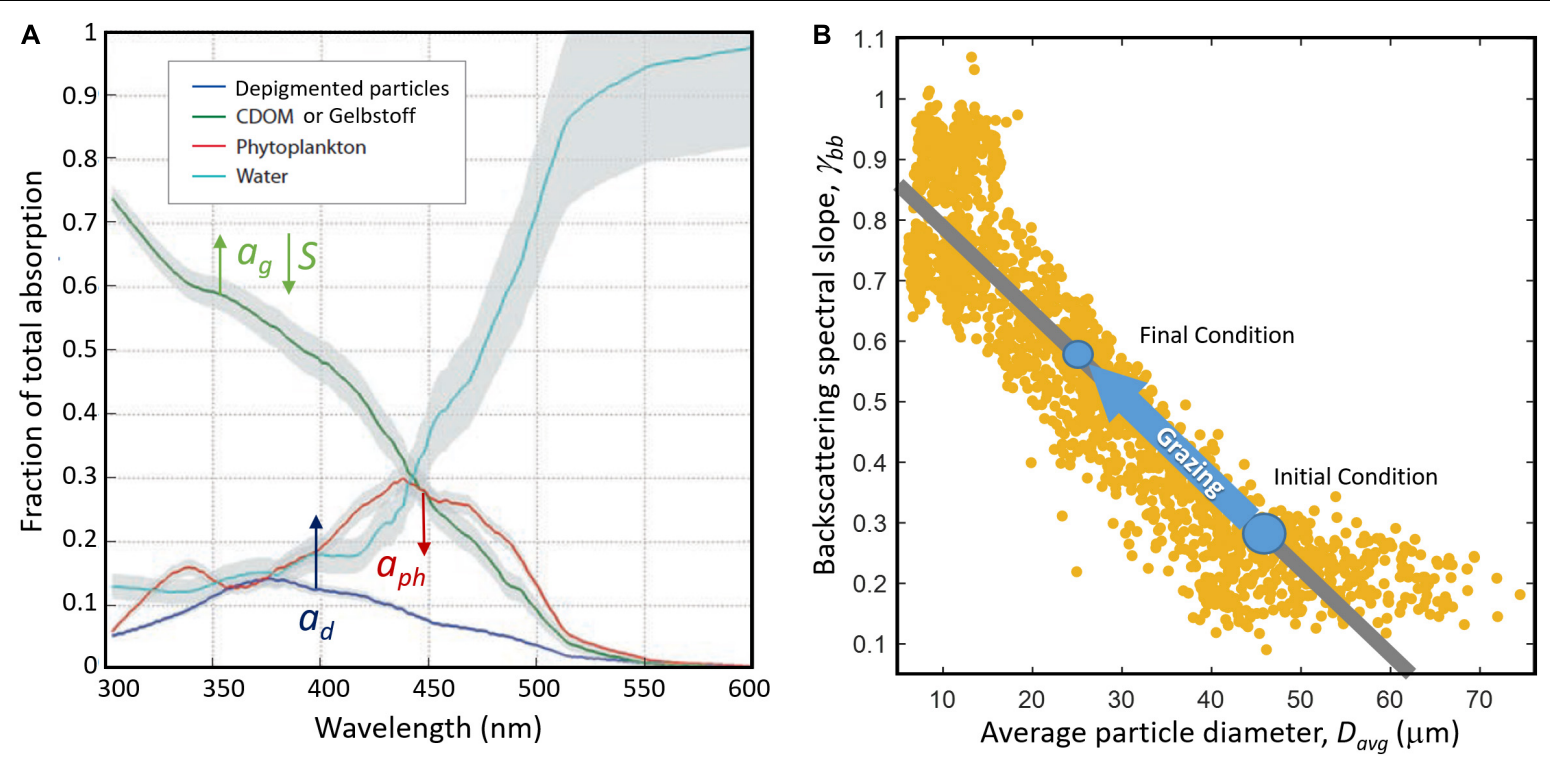

FIGURE 2 | Grazing is hypothesized to change spectral absorption and backscattering across UV and visible wavelengths. (A) As particles are grazed, absorption by gelbstoff $\left(a_{g}\right)$ may increase and the spectral slope $(S)$ may flatten compared to background gelbstoff subject to photobleaching. The contribution of depigmented particle absorption $\left(a_{d}\right)$ may increase and phytoplankton absorption $\left(\mathrm{a}_{p h}\right)$ may decrease as particles are grazed. The relative changes in these components result in spectral dips and troughs that may be observed in the remote sensing reflectance, particularly in sensors that can detect spectral changes in the UV like PACE. Modified from Nelson and Siegel (2013). (B) Backscattering is expected to increase with increased detrital matter produced by grazing. In addition, we hypothesize that the spectral slope of backscattering $g_{\gamma}$, will increase as the average particle size decreases with decreasing phytoplankton and increasing detrital particles. Modified from Slade et al. (2015) showing trends in these parameters from field measurements.

time series approaches are possible, and increasing resolution by satellites will increase the opportunities for this approach, we still lack the ability to remotely retrieve direct signals of grazing (Brewin et al., 2021). Two inherent optical properties (IOPs) commonly related to remote sensing include spectral absorption $a(\lambda)$ and scattering $b(\lambda)$ coefficients ( $\lambda$ is the wavelength), describing the amount of a light beam absorbed or scattered per unit distance within the medium (units $\mathrm{m}^{-1}$; see Mobley, 1994; Dierssen and Randolph, 2013). Oceanic constituents that are primarily responsible for absorption of photons include water molecules, phytoplankton pigments, particulate detritus, minerogenic material, and colored dissolved organic material. Scattering processes occur at the boundary of a particle with a different index of refraction from the surrounding water. Both absorption and scattering processes create targets for satellite retrieval of ocean color in terms of the magnitude and spectral shape of reflected light. Here we suggest that grazing will affect absorption and scattering properties and have the potential to be detected with ocean color remote sensing techniques (Figure 1).

\section{Absorption}

There is an urgent need and great opportunity to identify changes in absorption over time associated with grazing and to explore potential optical proxies for grazing rates that can be applied to remote sensing imagery. The total absorption coefficient of seawater is often represented in terms of the sum of the pure water component $a_{w}(\lambda)$, a particulate component $a_{p}(\lambda)$, and a dissolved or "gelbstoff" component $a_{g}(\lambda)$ that is operationally defined as anything that passes through a $0.2-\mu \mathrm{m}$ filter. Dissolved matter can include pigment-like components, amino acid or protein-like components and small colloids that pass through the filter.

The particulate absorption coefficient can be further partitioned into a phytoplankton component $a_{p h}(\lambda)$ and a component related to depigmented particles $a_{d}(\lambda)$ that has traditionally been referred to as non-algal or detrital particles, which include depigmented algal particles, detritus generated through feeding, as well as minerals and suspended sediment. The spectral shapes of both $a_{g}(\lambda)$ and $a_{d}(\lambda)$ are smooth monotonically decreasing functions. Because of the similarity in spectral shape, it is often challenging to separate these components optically with multi-channel sensors, and the two are often combined in remote sensing approaches like the Generalized Inherent Optical Properties algorithm (GIOP; Werdell et al., 2013) or quasi-analytical algorithm (QAA; Lee et al., 2002) models. The sources and sinks of these two constituents are quite different and the combination is challenging to interpret from a biogeochemical perspective.

With the advent of hyperspectral sensors like those in development for future NASA missions (e.g., geosynchronous littoral imaging and monitoring radiometer (GLIMR), and surface biology and geology (SBG) missions (Dierssen et al., 2021), models are being proposed to separate the relative contributions of $a_{d}(\lambda)$ and $a_{g}(\lambda)$ in the surface ocean from the remote sensing signal globally. An important component will be to investigate the influence of grazing on IOPs in a controlled setting to identify applications to the suite of new measurement technology in the pipeline for these new missions. 
For example, new methods have been proposed to improve partitioning of total absorption into the three components, $a_{p h}(\lambda), a_{d}(\lambda)$ and $a_{g}(\lambda)$ with an inversion scheme (Zheng et al., 2015; Stramski et al., 2019). The ability to partition absorption into its components may provide information on primary production and associated grazing.

\section{Scattering}

As with absorption, changes in scattering provides another opportunity to link grazing, optical properties, and remote sensing. Scattering is inherently an angle-dependent process, described by the volume scattering function [VSF, $\beta(\psi, \lambda)$, units $\left.\mathrm{m}^{-1} \mathrm{sr}^{-1}\right]$, where $\psi$ is the scattering angle relative to the incident light. The magnitude, angular shape, and polarization properties of scattering by particles in seawater are dependent on particle size, shape, and composition. Associations between particle properties and optical scattering properties allow for proxy models to estimate a wide range of particle properties and dynamics in situ (e.g., Sullivan et al., 2005).

Measurement of the particulate backscattering coefficient $b_{b p}(\lambda)$ (essentially the integral of the VSF over the backward hemisphere) is of particular importance since it is a critical element of understanding ocean color remote sensing signals (Werdell et al., 2018, references therein), which are being used to describe global-scale biogeochemical processes and changes therein due to climate change (e.g., Siegel et al., 2016; Dutkiewicz et al., 2019). Backscattering measurements are also becoming common on autonomous platforms where they have recently been used to constrain biogeochemical processes (e.g., Mignot et al., 2018; Uchida et al., 2019). Fluctuations in the optical properties can also be used to estimate particle size (Briggs et al., 2013). This concept was expanded by leveraging fluctuations in the backscattering signal during a flux event to partition the stock into multiple size fractions to examine the effect of fragmentation of settling aggregates on carbon flux (Briggs et al., 2020).

Theoretical work has suggested that the scattering or backscattering spectral shape depends on the PSD (e.g., Morel, 1973; Boss et al., 2001, references therein). Limited indirect measurements of backscattering using in situ radiometric or ocean color (Loisel et al., 2006; Gordon et al., 2009) and direct measurements of spectral backscattering and PSD (Slade et al., 2015) support the possibility of spectral backscattering as a proxy for particle size. The shape of the VSF measured at multiple angles can also be used to invert for PSD and composition (e.g., organic vs. mineral) using a variety of approaches (e.g., Agrawal and Pottsmith, 2000; Zhang et al., 2011).

Polarization of scattering by particles in the ocean is also expected to depend on PSD and composition, however, only limited measurements have been made in situ or of ocean samples (Voss and Fry, 1984; Koestner et al., 2018). The most detailed examinations of angular dependence of polarized scattering have been of phytoplankton cultures (Volten et al., 1998; Svensen et al., 2011), where significant differences were found between measurements and theoretical predictions for a wide range of cell sizes, shapes, and structures. Thus, there remains need and opportunity to unify theoretical expectations with empirical observations of phytoplankton scattering functions, both under controlled laboratory conditions and those representative of the heterogeneous and dynamic ocean.

\section{DISCUSSION}

\section{Linking Grazing and Optics: A Possible Path Forward}

To explore the utility of optical properties for the quantitative analysis of grazing pressure in marine planktonic food webs, we envision a collaborative effort that closely ties the research needs with instrument development. These could leverage existing instrumentation and methods (Table 1) to measure grazing impacts on particle fields (Menden-Deuer et al., 2020), scattering and PSD relationships (Slade et al., 2015), dissolved and detrital absorption, as well as changes in phytoplankton absorption and pigments (Figure 2). The overall concept is to measure removal of algal prey by zooplankton first in laboratory grazing experiments. These experiments consist of bottle incubations that pair a grazer and a phytoplankton prey species and a control of the phytoplankton species incubated by itself (Frost, 1972; Jeong, 2007). The predator-free control allows to estimate the effects of other sources of mortality and the magnitude of growth in the absence of grazing. Experiments with targeted single predator prey pairs provide a best-case scenario approach to maximize the signal to noise ratio and examine the sensitivity of existing instruments to these idealized conditions.

Since this is exploratory research with well-founded hypotheses, but without prior empirical support, a broad net needs to be cast to determine grazer induced changes in optical properties both in the particulate and dissolved phases. Measuring abundance, PSD, angular and polarized scattering, and absorption of the dissolved and particulate (algal and non-algal) components, can aid in delivering diagnostic data linking optical properties to grazing pressure, qualitatively (presence or absence of grazing) and quantitatively (across a prey concentration gradient; Figure 2). Finally, to examine the utility of these idealized measurements for remote sensing applications, the absorption and scattering measurements can be examined in terms of their individual and combined effects on ocean color signals using a radiative transfer model such as HydroLight (Hedley and Mobley, 2019).

Once promising targets for optical grazing signatures are identified, field experiments can commence to probe grazing measurements that utilize incubations (e.g., Morison and Menden-Deuer, 2017) for correlations between optical proxies and concurrent measurements of grazing rates. The final testing goal would then be to characterize the optical properties in situ and probe for grazing signatures at high resolution over large spatial and temporal scales. Such measurements would open the door to test ocean color remote sensing algorithms for retrieving IOPs under different grazing conditions. Obviously, this would require in situ validation and inter-comparison efforts and could benefit from leveraging existing data sets with concurrent optical measurements and grazing incubations for retrospective analysis, as available. 
TABLE 1 | Examples of measurement approaches that can aid in quantifying grazing impacts on the optical properties of seawater, their methodologies, applicability to lab and/or field studies, and estimated uncertainties.

\begin{tabular}{|c|c|c|c|c|}
\hline Measurement & Quantities (units) & Instrument/Method & Lab/Field & Uncertainty \\
\hline \multirow[t]{2}{*}{ Predator/prey concentration } & Abundance (cells mL $\mathrm{mL}^{-1}$ ) & $\begin{array}{l}\text { Microscopy/Image analysis } \\
\text { (provides cell characteristics) }\end{array}$ & Lab, Field In situ & $\pm 10 \%$ (Menden-Deuer et al., 2020) \\
\hline & & $\begin{array}{l}\text { Coulter Counter (CC) (rapid } \\
\text { processing but no cell } \\
\text { characteristics) }\end{array}$ & Lab, Field Discrete & $\pm 1 \%$ (Menden-Deuer et al., 2020) \\
\hline Predator/prey biomass & Biomass $\left(\mu \mathrm{gC} \mathrm{L}^{-1}\right)$ & Microscopy/Image Analysis & Lab, Field In situ & $\begin{array}{l} \pm 30 \% \text { (Menden-Deuer and Lessard, } \\
2000 \text { ) }\end{array}$ \\
\hline \multirow[t]{2}{*}{ Grazing rate } & $\begin{array}{l}\text { Change in Abundance } \\
\text { (cells predator }^{-1} \text { day }^{-1} \text { ) } \\
\text { and Biomass }(\mu \mathrm{gC} \\
\text { predator }^{-1} \text { day }^{-1} \text { ) }\end{array}$ & Microscopy/Image analysis & Lab, Field In situ & $\begin{array}{l} \pm 10 \% \text { of algal counts (Menden-Deuer } \\
\text { et al., 2018) }\end{array}$ \\
\hline & & Coulter Counter & Lab, Field Discrete & \\
\hline \multirow[t]{3}{*}{ Particle size } & $\mathrm{PSD}, N(D)(\# / \mathrm{mL})$ & Coulter Counter & Lab, Field Discrete & $\pm 1 \%$ (Menden-Deuer et al., 2020) \\
\hline & PSD, $V(D)(\mu\llcorner/ L)$ & LISST-200X & Lab, Field In situ & $\begin{array}{l}\text { Approx. 3\% D50 repeatability (ISO, } \\
\text { 2020) }\end{array}$ \\
\hline & $D_{\text {avg }}(\mu \mathrm{m})$ & $\begin{array}{l}\text { Optical signal fluctuations in } c_{p} \text { and } \\
b_{b p}\end{array}$ & Lab, Field In situ & 10\%-24\% (Briggs et al., 2013) \\
\hline \multirow[t]{2}{*}{ Particulate absorption } & $a_{p}(\lambda)\left(m^{-1}\right)$ & QFT-ICAM & Lab, Field Discrete & $\pm 1.5 \%$ (Röttgers et al., 2016) \\
\hline & & ac-9/ac-s & Lab, Field, In situ & $\pm 0.006 \mathrm{~m}^{-1 a}$ (Twardowski et al., 2018) \\
\hline Particulate absorption (constituents) & $a_{d}(\lambda)\left(m^{-1}\right) a_{p h}(\lambda)\left(m^{-1}\right)$ & $\begin{array}{l}\text { Models for partitioning particulate } \\
\text { absorption into } a_{d}(\lambda) \text { and } a_{p h}(\lambda)\end{array}$ & Model & Stramski et al., 2019 \\
\hline \multirow[t]{2}{*}{ Phytoplankton community composition } & & Imaging methods FlowCytometry & Lab, Field In situ & (see Lombard et al., 2019) \\
\hline & & Diagnostic Pigment Analysis & Lab, Field Discrete & Chase et al., 2020 \\
\hline \multirow[t]{2}{*}{ Dissolved absorption } & $a_{g}(\lambda)\left(m^{-1}\right)$ & Spectrometry & Lab, Field Discrete & $\begin{array}{l}\text { 10\% wavelength-dependent (IOCCG, } \\
2018 \text { ) }\end{array}$ \\
\hline & & ac-9/ac-s & Lab, Field, In situ & $\pm 0.001 \mathrm{~m}^{-1 a}$ (Twardowski et al., 2018) \\
\hline \multirow[t]{2}{*}{ Particulate attenuation } & $c_{p}(\lambda)\left(m^{-1}\right)$ & ac-9/ac-s & Lab, Field, In situ & $\begin{array}{l}<0.004 \mathrm{~m}^{-1 a, b} \text { (IOCCG Protocol } \\
\text { Series, 2019) }\end{array}$ \\
\hline & $c_{p}(520)\left(\mathrm{m}^{-1}\right)$ & LISST optics & Lab, Field, In situ & $<0.01 \mathrm{~m}^{-1}$ \\
\hline Volume scattering function (VSF) & $\beta_{p}(\psi, 520)\left(\mathrm{m}^{-1} \mathrm{sr}^{-1}\right)$ & LISST-Horizon(2) LISST-VSF & Lab, Field, In situ & $\begin{array}{l}\text { Typ. 3-10\% uncertainty (Zhang et al., } \\
\text { 2011) }\end{array}$ \\
\hline \multirow[t]{2}{*}{ Backscattering } & $b_{b p}(700)\left(m^{-1}\right)$ & ECO-VSF & Lab, Field In situ & $\pm 5-10 \%$ relative (Sullivan et al., 2013) \\
\hline & $b_{b p}(520)\left(m^{-1}\right)$ & $\begin{array}{l}\text { Extrapolation and integration of } \\
\text { measured VSF (LISST-VSF) }\end{array}$ & Lab, Field In situ & To be determined \\
\hline Turbidity & TSS (NTU) & Turbidimeter & Lab, Field In situ & 〜55\% (Boss et al., 2009) \\
\hline \multirow[t]{2}{*}{ Particulate scattering } & $b_{p}(\lambda)\left(\mathrm{m}^{-1}\right)$ & ac-9/ac-s & Lab, Field In situ & $\pm 0.007^{a, b} \mathrm{~m}^{-1}$ (Sullivan et al., 2013) \\
\hline & $b_{p}(520)\left(m^{-1}\right)$ & $\begin{array}{l}\text { Extrapolation and integration of } \\
\text { measured VSF }\end{array}$ & Lab, Field In situ & To be determined \\
\hline Polarized scattering & DoLP & LISST-Horizon LISST-VSF & Lab, Field In situ & To be determined \\
\hline
\end{tabular}

approximately double this for short blue and long red wavelengths.

${ }^{b}$ plus $\sim 5-10 \%$ underestimation from scattered light $<0.8$ not detected.

Absorption, attenuation and scattering instrumentation will require additional innovation to tailor measurements for the proposed grazing studies.

While laboratory experiments will provide a linkage between IOPs and grazing under idealized conditions, field experiments will also be required to assess grazing under realistic environmental conditions. This approach will provide an understanding of grazing with changing predator and prey compositions and physical conditions including turbulence and mixing. Under such conditions, particle imaging techniques will be useful to assess the distribution, sizes and types of particles (Lombard et al., 2019) potentially impacted by grazing. Techniques like holography can provide particle imaging in a large undisturbed sample volume without disturbance of the particle orientation (Nayak et al., 2018). Several different commercially available holographic imaging instruments are now being offered (Walcutt et al., 2020).

\section{The Case for Science-Industry Partnerships}

Research scientists, often in government or academic settings, typically do not have the facilities, expertise, and leeway to pursue de-novo instrument development. Instrument vendors, on the other hand, typically need to rely on broad application of their existing instrumentation and do not have the economic incentive to develop instruments for a novel application. Through a partnership, instrument developments can be tailored 
to urgent measurement gaps. However, these partnerships can be difficult to frame as collaborative proposals, where the risk of instrumentation development often does not fit into panel review criteria. Neither do these efforts fit into technology development funding calls such as through the US SBIR/STTR program, since there may not be a clear commercialization potential.

Specifically, a commercial-academic partnership is needed when, as in our case, there are many unknowns associated with a particular research endeavor. Although the question is important and developing remote sensing approaches for grazing would be transformative, there are two major obstacles. First, there is no current technology to measure grazing other than through incubation methods; and second, although we have half a dozen or more possible targets, there has been no specific target identified. This situation is utterly unattractive to instrument developers. The cost to generate a new instrument is approximately 10 -fold greater than modification of an existing one. To incentivize the development, we propose that much of the research effort of identifying a target should be done by academic partners at the cutting edge of the field. Bringing instrument developers on board right away provides opportunities to possibly modify existing technology in support of novel science applications.

In the case we have outlined here, there are clear opportunities for science-industry collaboration. For the laboratory effort, a variety of angular, spectral, and polarized scattering measurements are made to address the hypothesis that grazing changes the IOP of seawater in characteristic ways. It is unrealistic for the project to absorb the costs associated with acquiring, maintaining, and developing expertise around a full suite of instrumentation to examine possible scattering-based biogeochemical proxies. Providing the ability to lease instruments with associated consulting services may enhance science and industry partnerships that provide high quality data at more cost-effective rates than purchasing new instrumentation and training personnel. Close involvement of the industrial partner in the experimental design helps to ensure that instrument modifications, method development, and/or prototype development is focused on the needs of the science partners and is technically feasible and potentially comercializable. This arrangement provides the additional benefit for the industrial partner to test new instruments and

\section{REFERENCES}

Agrawal, Y. C., and Pottsmith, H. C. H. (2000). Instruments for particle size and settling velocity observations in sediment transport. Mar. Geol. 168, 89-114. doi: 10.1016/S0025-3227(00)00044-X

Behrenfeld, M. J. (2010). Abandoning Sverdrup's critical depth hypothesis on phytoplankton blooms. Ecology 91, 977-989. doi: 10.1890/09-1207.1

Bisson, K., Siegel, D. A., and DeVries, T. (2020). Diagnosing mechanisms of ocean carbon export in a satellite-based food web model. Front. Mar. Sci. 7:505. doi: $10.3389 /$ fmars.2020.00505

Boss, E., Taylor, L., Gilbert, S., Gundersen, K., Hawley, N., Janzen, C., et al. (2009). Comparison of inherent optical properties as a surrogate for particulate matter concentration in coastal waters. Limnol. Oceanogr. Methods 7, 803-810. doi: 10.4319/lom.2009.7.803 methodologies in the field, often a costly and logistically difficult proposition, especially for a small company.

When new technology developments are successful and commercially viable, science and industry partnerships thrive. In this manner, a high-risk, high-reward project of identifying novel optical proxies can hold immense value in breaking new scientific grounds as well as stimulating adoption of existing technology to novel applications and development of new technology. Here, we have outlined how the pressing scientific question of assessing global grazing rates requires a host of new optical measurements that could be used to enhance science and industry partnerships and lead to much needed scientific capacities to understand ocean ecosystems and carbon flux.

\section{DATA AVAILABILITY STATEMENT}

The datasets presented in the study are included in the article, further inquiries can be directed to the corresponding author/s.

\section{AUTHOR CONTRIBUTIONS}

All authors listed have made a substantial, direct and intellectual contribution to the work, and approved it for publication.

\section{FUNDING}

Support for SM-D was provided by the National Aeronautics and Space Administration (80NSSC17K0716) and the National Science Foundation (OCE-1736635). Support for HD was provided by NASA (80NSSC20M0206).

\section{ACKNOWLEDGMENTS}

We thank Ivona Cetinic for facilitating initial discussion of this work and Sara Shapiro for creating the drawing for Figure 1. We appreciate careful review and comments from two reviewers who have improved this manuscript.

Boss, E., Twardowski, M. S., and Herring, S. (2001). Shape of the particulate beam attenuation spectrum and its inversion to obtain the shape of the particulate size distribution. Appl. Opt. 40:4885. doi: 10.1364/AO.40.004885

Brewin, R. J. W., Sathyendranath, S., Platt, T., Bouman, H., Ciavatta, S., Dall'Olmo, G., et al. (2021). Sensing the ocean biological carbon pump from space: a review of capabilities, concepts, research gaps and future developments. Earth Sci. Rev. 217:103604. doi: 10.1016/j.earscirev.2021.103604

Briggs, N., Dall'Olmo, G., and Claustre, H. (2020). Major role of particle fragmentation in regulating biological sequestration of $\mathrm{CO} 2$ by the oceans. Science 793, 791-793. doi: 10.1126/science.aay1790

Briggs, N. T., Slade, W. H., Boss, E. S., and Perry, M. J. (2013). Method for estimating mean particle size from high-frequency fluctuations in beam attenuation or scattering measurements. Appl. Opt. 52, 6710-6725. doi: 10. 1364/AO.52.006710 
Buonassissi, C. J., and Dierssen, H. M. (2010). A regional comparison of particle size distributions and the power law approximation in oceanic and estuarine surface waters. J. Geophys. Res. 115, 1-12. doi: 10.1029/2010JC0 06256

Calbet, A. (2001). Mesozooplankton grazing effect on primary production: a global comparative analysis in marine ecosystems. Limnol. Oceanogr. 46, 1824-1830. doi: 10.4319/lo.2001.46.7.1824

Calbet, A., and Landry, M. R. (2004). Phytoplankton growth, microzooplankton grazing, and carbon cycling in marine systems. Limnol. Oceanogr. 49, 51-57. doi: 10.4319/lo.2004.49.1.0051

Chase, A. P., Kramer, S. J., Haëntjens, N., Boss, E. S., Karp-Boss, L., Edmondson, M., et al. (2020). Evaluation of diagnostic pigments to estimate phytoplankton size classes. Limnol. Oceanogr. Methods 18, 570-584. doi: 10.1002/lom3.10385

Dall'Olmo, G., Westberry, T. K., Behrenfeld, M. J., Slade, W. H., Boss, E. S., and Slade, W. H. (2009). Significant contribution of large particles to optical backscattering in the open ocean. Biogeosciences 6, 947-967. doi: 10.5194/bg-6947-2009

Dierssen, H. M., Ackleson, S., Joyce, K., Hestir, E., Castagna, A., Lavender, S., et al. (2021). Living up to the hype of hyperspectral aquatic remote sensing: science, resources and outlook. Front. Environ. Sci. 9:134. doi: 10.3389/fenvs. 2021.649528

Dierssen, H. M., and Randolph, K. (2013). "Remote sensing of ocean color, in Earth System Monitoring, ed. J. Orcutt (New York, NY: Springer New York), 439-472. doi: 10.1007/978-1-4614-5684-1_18

Dutkiewicz, S., Hickman, A. E., Jahn, O., Henson, S., Beaulieu, C., and Monier, E. (2019). Ocean colour signature of climate change. Nat. Commun. 10:578. doi: 10.1038/s41467-019-08457-x

Frost, B. W. (1972). Effects of size and concentration of food particles on the feeding behavior of the marine planktonic copepod Calanus pacificus. Limnol. Oceanogr. 17, 805-815. doi: 10.4319/lo.1972.17.6.0805

Gordon, H. R., Lewis, M. R., McLean, S. D., Twardowski, M. S., Freeman, S. A., Voss, K. J., et al. (2009). Spectra of particulate backscattering in natural waters. Opt. Express 17, 16192-16208. doi: 10.1364/OE.17.016192

Hedley, J. D., and Mobley, C. D. (2019). HydroLight 6.0 Users' Guide. Tiverton: Numerical Optics Ltd.

IOCCG (2018). IOCCG Ocean Optics and Biogeochemistry Protocols for Satellite Ocean Colour Sensor Validation. Inherent Optical Property Measurements and Protocols: Absorption Coefficient, Vol. 1.0, eds. A. R. Neeley and A. Mannino [Dartmouth, NS: International Ocean-Colour Coordinating Group (IOCCG)], 78. doi: 10.25607/OBP- 119

IOCCG Protocol Series (2019). Beam Transmission and Attenuation Coefficients: Instruments, Characterization, Field Measurements and Data Analysis Protocols. Available online at: http://dx.doi.org/10.25607/OBP-458

ISO (2020). Particle Size Analysis - Laser Diffraction Methods. Geneva. Available online at: https://www.iso.org/standard/69111.html

Jeong, H. J. (2007). The ecological roles of heterotrophic dinoflagellates in marine planktonic community. J. Eukaryot. Microbiol. 46, 390-396. doi: 10.1111/j. 1550-7408.1999.tb04618.x

Koestner, D., Stramski, D., and Reynolds, R. A. (2018). Measurements of the volume scattering function and the degree of linear polarization of light scattered by contrasting natural assemblages of marine particles. Appl. Sci. 8, 1-32. doi: 10.3390/app8122690

Landry, M. R., and Hassett, R. (1982). Estimating the grazing impact of marine micro-zooplankton. Mar. Biol. 67, 283-288. doi: 10.1007/bf00397668

Landry, M. R., Ohman, M. D., Goericke, R., Stukel, M. R., and Tsyrklevich, K. (2009). Lagrangian studies of phytoplankton growth and grazing relationships in a coastal upwelling ecosystem off Southern California. Prog. Oceanogr. 83, 208-216. doi: 10.1016/j.pocean.2009.07.026

Lee, Z., Carder, K. L., and Arnone, R. A. (2002). Deriving inherent optical properties from water color: a multiband quasi-analytical algorithm for optically deep waters. Appl. Opt. 41:5755. doi: 10.1364/AO.41.005755

Loisel, H., Nicolas, J.-M., Sciandra, A., Stramski, D., and Poteau, A. (2006). Spectral dependency of optical backscattering by marine particles from satellite remote sensing of the global ocean. J. Geophys. Res. 111, 1-14. doi: 10.1029/ 2005JC003367

Lombard, F., Boss, E. S., Waite, A. M., Uitz, J., Stemmann, L., Sosik, H. M., et al. (2019). Globally consistent quantitative observations of planktonic ecosystems. Front. Mar. Sci. 6:196. doi: 10.3389/fmars.2019.00196
Mariani, P., Andersen, K. H., Visser, A. W., Barton, A. D., and Kiørboe, T. (2013). Control of plankton seasonal succession by adaptive grazing. Limnol. Oceanogr. 58, 173-184. doi: 10.4319/lo.2013.58.1.0173

McNair, H., Morison, F., Graff, J., Rynerason, T., and Menden-Deuer, S. (2021). Microzooplankton grazing constrains pathways of carbon export in the subarctic North Pacific. Limnol. Oceanogr. 66, 2697-2711. doi: 10.1002/lno. 11783

McNair, H. M., and Menden-Deuer, S. (2020). Protist grazing contributes to microbial food web at the upper boundary of the twilight zone in the subarctic Pacific. Mar. Ecol. Prog. Ser. 636, 235-241. doi: 10.3354/meps13246

Menden-Deuer, S., and Kiørboe, T. (2016). Small bugs with a big impact: linking plankton ecology with ecosystem processes. J. Plankton Res. 38, 1036-1043. doi: 10.1093/plankt/fbw049

Menden-Deuer, S., Lawrence, C., and Franzé, G. (2018). Herbivorous protist growth and grazing rates at in situ and artificially elevated temperatures during an Arctic phytoplankton spring bloom. PeerJ 6:e5264. doi: 10.7717/peerj. 5264

Menden-Deuer, S., and Lessard, E. J. (2000). Carbon to volume relationships for dinoflagellates, diatoms, and other protist plankton. Limnol. Oceanogr. 45, 569-579. doi: 10.4319/lo.2000.45.3.0569

Menden-Deuer, S., Lessard, E., Satterberg, J., and Grünbaum, D. (2005). Growth rates and starvation survival of three species of the pallium-feeding, thecate dinoflagellate genus Protoperidinium. Aquat. Microb. Ecol. 41, 145-152. doi: 10.3354/ame041145

Menden-Deuer, S., Morison, F., Montalbano, A. L., Franzè, G., Strock, J., Rubin, E., et al. (2020). Multi-instrument assessment of phytoplankton abundance and cell sizes in mono-specific laboratory cultures and whole plankton community composition in the North Atlantic. Front. Mar. Sci. 7:254. doi: 10.3389/fmars. 2020.00254

Mignot, A., Ferrari, R., and Claustre, H. (2018). Floats with bio-optical sensors reveal what processes trigger the North Atlantic bloom. Nat. Commun. 9:190. doi: 10.1038/s41467-017-02143-6

Mobley, C. D. (1994). Light and Water: Radiative Transfer in Natural Waters. San Diego, CA: Academic Press.

Morel, A. (1973). "Diffusion de la lumi'ere par les eaux de mer. R'esultats exp'erimentaux et approche th'eorique," in Optics of the Sea, AGARD Lect. Ser. 61, 3.1.1-76, Neuilly-sur-Seine: NATO. Available online at: https://apps.dtic.mil/sti/pdfs/AD0767474.pdf

Morison, F., Harvey, E., Franzè, G., and Menden-Deuer, S. (2019). Storm-induced predator-prey decoupling promotes springtime accumulation of north atlantic phytoplankton. Front. Mar. Sci. 6:608. doi: 10.3389/fmars.2019.00608

Morison, F., and Menden-Deuer, S. (2017). Doing more with less? Balancing sampling resolution and effort in measurements of protistan growth and grazing-rates. Limnol. Oceanogr. Methods 15, 794-809. doi: 10.1002/lom3. 10200

Morison, F., Pierson, J., Oikonomou, A., and Menden-Deuer, S. (2020). Mesozooplankton grazing minimally impacts phytoplankton abundance during spring in the Western North Atlantic. PeerJ 8:e9430. doi: 10.7717/peerj.9430

Nayak, A. R., McFarland, M. N., Sullivan, J. M., and Twardowski, M. S. (2018). Evidence for ubiquitous preferential particle orientation in representative oceanic shear flows. Limnol. Oceanogr. 63, 122-143. doi: 10.1002/lno.10618

Nelson, N. B., and Siegel, D. A. (2013). The global distribution and dynamics of chromophoric dissolved organic matter. Ann. Rev. Mar. Sci. 5, 447-476. doi: 10.1146/annurev-marine-120710-100751

Röttgers, R., Doxaran, D., and Dupouy, C. (2016). Quantitative filter technique measurements of spectral light absorption by aquatic particles using a portable integrating cavity absorption meter (QFT-ICAM). Opt. Express 24:A1. doi: 10. 1364/OE.24.0000A1

Schmoker, C., Hernández-León, S., and Calbet, A. (2013). Microzooplankton grazing in the oceans: impacts, data variability, knowledge gaps and future directions. J. Plankton Res. 35, 691-706. doi: 10.1093/plankt/fbt023

Siegel, D. A., Buesseler, K. O., Behrenfeld, M. J., Benitez-Nelson, C. R., Boss, E. S., Brzezinski, M. A., et al. (2016). Prediction of the export and fate of global ocean net primary production: The EXPORTS science plan. Front. Mar. Sci. 3:22. doi: $10.3389 /$ fmars. 2016.00022

Slade, W. H., and Boss, E. S. (2015). Spectral attenuation and backscattering as indicators of average particle size. Appl. Opt. 54, 7264-7277. doi: 10.1364/AO. 54.007264 
Steinberg, D. K., and Landry, M. R. (2017). Zooplankton and the ocean carbon cycle. Ann. Rev. Mar. Sci. 9, 413-444. doi: 10.1146/annurev-marine-010814015924

Stock, C., and Dunne, J. (2010). Controls on the ratio of mesozooplankton production to primary production in marine ecosystems. Deep Sea Res. Part I Oceanogr. Res. Pap. 57, 95-112. doi: 10.1016/j.dsr.2009.10.006

Stramski, D., Li, L., and Reynolds, R. A. (2019). Model for separating the contributions of non-algal particles and colored dissolved organic matter to light absorption by seawater. Appl. Opt. 58:3790. doi: 10.1364/AO.58.003790

Strom, S. L. (2007). Microbial ecology of ocean biogeochemistry: a community perspective. Science 320:1043. doi: 10.1126/science.1153527

Strom, S. L., Benner, R., Ziegler, S., and Dagg, M. J. (1997). Planktonic grazers are a potentially important source of marine dissolved organic carbon. Limnol. Oceanogr. 42, 1364-1374. doi: 10.4319/lo.1997.42.6.1364

Sullivan, J., Twardowski, M., Zaneveld, J. R. V., and Moore, C. (2013). "Measuring optical backscattering in water," in Light Scattering Reviews 7: Radiative Transfer and Optical Properties of Atmosphere and Underlying Surface, Springer Praxis Books, ed. A. Kokhanovsky (Berlin: Springer), 189-224. doi: 10.1007/978-3642-21907-8_6

Sullivan, J. M., Twardowski, M. S., Donaghay, P. L., and Freeman, S. A. (2005). Use of optical scattering to discriminate particle types in coastal waters. Appl. Opt. 44, 1667-1680. doi: 10.1364/AO.44.001667

Svensen, $\varnothing$, Stamnes, J. J., Kildemo, M., Aas, L. M. S., Erga, S. R., and Frette, $\varnothing$ (2011). Mueller matrix measurements of algae with different shape and size distributions. Appl. Opt. 50, 5149-5157. doi: 10.1364/AO.50.005149

Twardowski, M., Freeman, S., Pegau, S., Zaneveld, J. R. V., Mueller, J., and Boss, E. (2018). "Chapter 2: reflective tube absorption meters," in IOCCG Absorption Protocol Protocols, Inherent Optical Property Measurements and Protocols, Vol. I, ed. A. Neely, 37-51.

Uchida, T., Balwada, D., Abernathey, R., Prend, C. J., Boss, E. S., and Gille, S. T. (2019). Southern Ocean phytoplankton blooms observed by biogeochemical floats. J. Geophys. Res. Ocean 124, 1-16. doi: 10.1029/2019JC015355

Verity, P. G. (1986). Grazing of phototrophic nanoplankton by microzooplankton in narragansett bay. Mar. Ecol. Prog. Ser. 29, 105-115. doi: 10.3354/meps029105

Volten, H., de Haan, J. F., Hovenier, J. W., Schreurs, R., Vassen, W., Dekker, A. G., et al. (1998). Laboratory measurements of angular distributions of light scattered by phytoplankton and silt. Limnol. Oceanogr. 43, 1180-1197. doi: 10.4319/lo.1998.43.6.1180

Voss, K. J., and Fry, E. S. (1984). Measurement of the Mueller matrix for ocean water. Appl. Opt. 23:4427. doi: 10.1364/AO.23.004427

Walcutt, N. L., Knörlein, B., Cetinić, I., Ljubesic, Z., Bosak, S., Sgouros, T., et al. (2020). Assessment of holographic microscopy for quantifying marine particle size and concentration. Limnol. Oceanogr. Methods 18, 516-530. doi: 10.1002/ lom 3.10379

Werdell, P. J., Franz, B. A., Bailey, S. W., Feldman, G. C., Boss, E. S., Brando, V. E., et al. (2013). Generalized ocean color inversion model for retrieving marine inherent optical properties. Appl. Opt. 52, 2019-2037. doi: 10.1364/AO. 52.002019

Werdell, P. J., McKinna, L. I. W., Boss, E., Ackleson, S. G., Craig, S. E., Gregg, W. W., et al. (2018). An overview of approaches and challenges for retrieving marine inherent optical properties from ocean color remote sensing. Prog. Oceanogr. 160, 186-212. doi: 10.1016/j.pocean.2018.01.001

Worden, A. Z., Follows, M. J., Giovannoni, S. J., Wilken, S., Zimmerman, A. E., and Keeling, P. J. (2015). Rethinking the marine carbon cycle: factoring in the multifarious lifestyles of microbes. Science. 347:1257594. doi: 10.1126/science. 1257594

Zhang, X., Twardowski, M., and Lewis, M. (2011). Retrieving composition and sizes of oceanic particle subpopulations from the volume scattering function. Appl. Opt. 50:1240. doi: 10.1364/AO.50.001240

Zheng, G., Stramski, D., and DiGiacomo, P. M. (2015). A model for partitioning the light absorption coefficient of natural waters into phytoplankton, nonalgal particulate, and colored dissolved organic components: a case study for the Chesapeake Bay. J. Geophys. Res. Ocean. 120, 2601-2621. doi: 10.1002/ 2014JC010604

Conflict of Interest: WS is Vice President for Science \& Technology at Sequoia Scientific, Inc.

The remaining authors declare that the development of this perspective was conducted in the absence of any commercial or financial relationships that could be construed as a potential conflict of interest.

Publisher's Note: All claims expressed in this article are solely those of the authors and do not necessarily represent those of their affiliated organizations, or those of the publisher, the editors and the reviewers. Any product that may be evaluated in this article, or claim that may be made by its manufacturer, is not guaranteed or endorsed by the publisher.

Copyright (c) 2021 Menden-Deuer, Slade and Dierssen. This is an open-access article distributed under the terms of the Creative Commons Attribution License (CC BY). The use, distribution or reproduction in other forums is permitted, provided the original author(s) and the copyright owner(s) are credited and that the original publication in this journal is cited, in accordance with accepted academic practice. No use, distribution or reproduction is permitted which does not comply with these terms. 